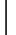

\title{
Impact of Alzheimer's Disease, Lewy Body and Vascular Co-Pathologies on Clinical Transition to Dementia in a National Autopsy Cohort
}

\author{
Jagan A. Pillai ${ }^{a-c}$ Robert S. Butler ${ }^{d}$ Aaron Bonner-Jackson ${ }^{a-c}$ \\ James B. Leverenz ${ }^{a-c}$ \\ ${ }^{a}$ Lou Ruvo Center for Brain Health, ${ }^{b}$ Neurological Institute, and Departments of \\ ${ }^{\mathrm{c}}$ Neurology and d Quantitative Health Sciences, Cleveland Clinic, Cleveland, Ohio, USA
}

\section{Key Words}

Alzheimer's disease - Dementia - Vascular dementia - Lewy body dementia - Mixed dementia $\cdot$ Rate of decline $\cdot$ Neuropathology

\begin{abstract}
Aims: We examined the effect of vascular or Lewy body co-pathologies in subjects with autopsy-confirmed Alzheimer's disease (AD) on the rate of cognitive and functional decline and transition to dementia. Methods: In an autopsy sample of prospectively characterized subjects from the National Alzheimer's Coordinating Center database, neuropathology diagnosis was used to define the groups of pure $A D(p A D, n=84)$, mixed vascular and $A D(A D V, n=54)$, and mixed Lewy body disease and $A D(A D L B D, n=31)$. Subjects had an initial Clinical Dementia Rating-Global (CDR-G) score $<1$, Mini-Mental State Examination $\geq 15$, a final visit CDR-G $>1, \geq 3$ evaluations, and Braak tangle stage $\geq$ III. We compared the rate of cognitive and functional decline between the groups. Results: The rate of functional and cognitive decline was lower for ADV, and ADV patients had less severe deficits on CDR-G and the CDR-Sum of Boxes scores at the last visit than $P A D$ and ADLBD patients. No significant differences were noted between $A D L B D$ and $P A D$ patients. After controlling for age at death, the odds of reaching CDR $\geq 1$ at the last visit were lower in the ADV subjects compared to the PAD subjects. Conclusions: The mean rate of functional and cognitive decline among ADV subjects was slower than among either pAD or ADLBD patients. Vascular pathology did not increase the odds of attaining CDR $\geq 1$ when occurring with $A D$ in this national cohort.

(C) 2016 S. Karger AG, Basel
\end{abstract}




\section{Introduction}

Mixed dementia (MD) is characterized by the co-occurrence of more than one type of neuropathology that contributes to cognitive decline. Multiple studies have suggested that MD is more common than previously recognized, with a significant proportion of subjects with dementia having mixed pathologies [1-8]. The prevalence rates of MD in autopsy series has been reported in the range from 2 to $56 \%$ in retrospective studies and from 2.9 to $54 \%$ in prospective studies [6]. Alzheimer's disease (AD) is found most commonly in combination with vascular disease (ADV), followed by Alzheimer's disease with Lewy body disease (ADLBD). Vascular dementia with LBD is less common [4, 7-9].

The nature of interaction between co-pathologies with $\mathrm{AD}$ in influencing functional and cognitive decline has been debated. Early studies noted the possibility that older individuals with neurofibrillary tangles and amyloid plaques have a lower threshold of dementia when there are co-occurring vascular lesions [10]. Vascular disease was noted to increase clinical dementia severity in persons with $\mathrm{AD}$ pathology $[1,11]$. Worse cognitive function with co-occurring vascular pathology in the lower pathologic stages of $\mathrm{AD}$, but notably not at higher levels of AD pathology, was also reported [12]. The rate of decline on Mini-Mental State Examination (MMSE) scores was noted to decrease slightly with advancing age for subjects with $\mathrm{AD}$ alone but increased with age for subjects with MD [13]. In these early reports, the numbers of subjects with MD in the autopsy series was often small, and due to the limited data not all subjects had longitudinal follow-ups of 3 or more years nor did they all start from a common pre-dementia baseline.

More recent studies, many with larger numbers of subjects, suggest a weaker direct interaction between vascular and $\mathrm{AD}$ pathologies or even both being independent processes. The Religious Orders study noted that beyond their additive effect, infarctions do not increase the likelihood of dementia [14]. In a clinical study using AD biomarkers, cardiovascular risk profiles were not predictive of progression in cerebrospinal fluid $\beta_{42}$-amyloid, $\left[{ }^{18} \mathrm{~F}\right]$ fluorodeoxyglucose positron emission tomography uptake and MRI hippocampal atrophy [15], while another reported that amyloid burden and vascular risk were found to interact in the parietal brain region alone [16]. Among cognitively normal elderly participants, a recent study, using imaging correlates of amyloid and vascular pathology, noted that amyloid and vascular pathologies seem to be at least partly independent processes and that both have an adverse impact on longitudinal cognitive trajectories [17]. An evidence-based review did not find strong support for the proposition that vascular risk factors increase AD pathology [18]. Studies evaluating the rate of cognitive decline among nondemented elders in the Rush Memory and Aging project and Religious Orders Study noted that macroscopic and microinfarcts were not significantly associated with a faster rate of decline on a global cognition measure when compared to the presence of amyloid pathology alone $[14,19]$.

Following these reports, the impact of vascular co-pathology on cognitive decline among subjects with $\mathrm{AD}$ pathology is again of intense interest. An outstanding question from this literature is whether ADV patients are more likely to have a faster progression and more severe cognitive and functional deficits before death than those with AD pathology alone. An autopsy cohort with mixed AD and vascular co-pathology and pure AD (pAD) diagnoses from a national sample who developed dementia during their longitudinal follow-up is necessary to complement previous reports.

Among MD patients with ADLBD, similar controversy reigns on the role of each of these pathologies in influencing the rate of cognitive and functional decline. In addition, in ADLBD cases both the amount and the topographical distribution of pathological protein aggregates (A $\beta$, phospho-tau, and $\alpha$-synuclein) were noted to have an impact on the clinical phenotype [20]. Co-occurrence of $\mathrm{AD}$ and LB pathology is common with studies reporting ADLBD in 
Pillai et al.: Impact of Alzheimer's Disease, Lewy Body and Vascular Co-Pathologies on

$14-26 \%$ of the demented patients, and 'pure' LBD in $0-19 \%$ of the demented subjects [5]. A meta-analysis of LBD studies noted comparable rates of decline in LBD and AD on MMSE [21]. Studies on MD reported faster decline among subjects with AD and LB co-pathology compared to pAD $[22,23]$. Among non-demented elders with AD and LB co-pathology, the Rush Memory and Aging project and Religious Orders Study noted that neocortical LBs were associated with a faster rate of decline (unlike the case for vascular co-pathology) [19]. The literature on co-occurring $\mathrm{LBD}$ and $\mathrm{AD}$ pathology on the rate of cognitive decline is smaller compared to ADV. The MD with LBD reports, similar to ADV reports, have smaller numbers of subjects in their analysis, and subjects were often not followed longitudinally starting from a predementia state to death in order to best characterize their rate of decline.

We undertook the current study in a national autopsy cohort, the National Alzheimer's Disease Coordinating Center (NACC), to characterize subjects with AD pathology with/ without vascular disease or LBD co-pathology. We examined: (1) the odds of dementia onset during longitudinal follow-up when all subjects started from a pre-dementia state [Clinical Dementia Rating (CDR) <1]; (2) the severity of cognitive and functional deficits in MD and pAD before death, and (3) the rate of cognitive and functional decline in MD and pAD. We hypothesized that subjects having mixed pathologies, that is, ADV and ADLBD, would have higher odds of onset of dementia before death, more severe cognitive and functional deficits at the last visit before death, and a faster rate of cognitive and functional decline than subjects with pAD.

\section{Methods}

\section{Materials and Methods}

The NACC maintains a database of participant information collected from 34 past and present AD centers funded by the National Institute on Aging. Data from the uniform data set (UDS) maintained by the NACC between September 2005 and May 2012 was used for the present analysis. Details on data collection and curating are well documented [24]. The CDR-Global (CDR-G) scale assesses the participant's current cognitive and functional status. The level of impairment in the domains or 'boxes' of memory, orientation, judgment and problem solving, community affairs, home and hobbies, and personal care are rated. The CDR-G ratings are calculated using a complex algorithm and range from 0 (no dementia) to 3 (severe dementia) [25]. The CDR Sum of Boxes (CDR-SB) is an operationalized measure of cognitive and functional ability. CDR-SB scores are calculated by simply adding the 'box scores' and range from 0 to 18 (higher scores indicate greater impairment).

For the purpose of this analysis, dementia was defined as CDR-G $\geq 1$. The rationale for subject inclusion/ exclusion criteria was to determine the likelihood of onset of dementia (transition to CDR-G $\geq 1$ ) across the groups and to reduce the potential effect of the large variability of initial cognitive deficits on the rate of decline analysis (by limiting initial CDR-G $<1$ and MMSE $>15$ ) [26]. By starting a longitudinal follow-up from a CDR-G $<1$, we hoped to facilitate comparison between subjects with similar initial severity of cognitive and functional deficits. All subjects included in the analysis had a final CDR-G score $\geq 1$ before death. The mean time from the last visit to death was $<1$ year. The subjects included in the analysis had a minimum of 3 longitudinal visits. Age at symptom onset was determined by the UDS question 'at what age did the cognitive decline begin' (based upon the clinician's assessment), and symptom duration was calculated from the age at death to symptom onset. Patient characteristics are described in table 1.

\section{Neuropathology}

The primary and secondary diagnosis for each of the subjects in the analysis was made by the neuropathologist at autopsy, based on the burden of pathology. AD pathology was noted as PAD if the primary pathologic diagnosis was $\mathrm{AD}$ and if there was no other contributing pathologic diagnosis. The neurofibrillary tangle stage in all MD cases was Braak stage III or greater and with moderate or frequent grading of neuritic and/ or diffuse plaques. The data on diffuse and neuritic plaques were also collected for all subjects. The ADV group was defined as those subjects with either a primary pathologic diagnosis of vascular disease with a 


\section{Dementia}

Cognitive Disorders

\begin{tabular}{l|l}
\hline \multicolumn{2}{l}{ Dement Geriatr Cogn Disord 2016;42:106-116 } \\
\hline DOI: 10.1159/000448243 & $\begin{array}{l}\text { @ 2016 S. Karger AG, Basel } \\
\text { www.karger.com/dem }\end{array}$ \\
\hline
\end{tabular}

Pillai et al.: Impact of Alzheimer's Disease, Lewy Body and Vascular Co-Pathologies on Clinical Transition to Dementia in a National Autopsy Cohort

Table 1. Patient characteristics

\begin{tabular}{lccc}
\hline & ADLBD & ADV & pAD \\
\hline Subjects, $\mathrm{n}$ & 31 & 54 & 84 \\
Female, \% & 29 & 50 & 46 \\
Education, years & $17.1(2.7)^{\mathrm{b}}$ & $14.5(2.8)^{\mathrm{a}, \mathrm{b}}$ & $15.9(2.8)^{\mathrm{a}}$ \\
APOE 4 4, \% & $61(\mathrm{n}=14)^{\mathrm{b}}$ & $40(\mathrm{n}=17)^{\mathrm{a}, \mathrm{b}}$ & $46(\mathrm{n}=29)^{\mathrm{a}}$ \\
Age at symptom onset (clinician's assessment), years & $71.3(8.1)^{\mathrm{b}}$ & $79.3(12.3)^{\mathrm{a}, \mathrm{b}}$ & $71.6(13.3)^{\mathrm{a}}$ \\
Age at change in CDR-G $\geq 1$, years & $77.6(8.2)^{\mathrm{b}}$ & $85.8(10.8)^{\mathrm{a}, \mathrm{b}}$ & $77.8(13.1)^{\mathrm{a}}$ \\
Age at death, years & $79.3(8.4)^{\mathrm{b}}$ & $87.5(10.2)^{\mathrm{a}, \mathrm{b}}$ & $80.0(12.9)^{\mathrm{a}}$ \\
Duration of symptoms, years & $8.1(2.8)$ & $7.7(3.5)$ & $8.5(3.4)$ \\
Time from last visit to death, years & $0.13(0.6)$ & $0.17(0.6)$ & $0.21(0.6)$ \\
\hline
\end{tabular}

Values are expressed as mean (SD), unless otherwise indicated. $p<0.01 .{ }^{a}$ Significant difference between $\mathrm{pAD}$ and ADV. ${ }^{\mathrm{b}}$ Significant difference between ADV and ADLBD.

contributing pathologic diagnosis of $\mathrm{AD}$ or a primary diagnosis of $\mathrm{AD}$ and a secondary diagnosis of vascular disease. The ADLBD group was defined as those subjects with both a primary pathologic diagnosis of LBD and a contributing pathologic diagnosis of AD or if the primary pathologic diagnosis was AD and LBD was a secondary diagnosis. Subjects with any other additional diagnoses listed were not considered for analysis. The minimum threshold of Braak stage III was chosen as just over half the individuals with Braak NFT stage III or IV and intermediate CERAD neuritic plaque score have been reported to have at least mild dementia in the NAAC data set [27]. The vascular pathology described at autopsy include: large infracts, micro infarcts, hemorrhages, lacunes, and arteriosclerosis. Details on NAAC vascular pathology coding have been previously described [28]. See online supplementary table 1 (for all online suppl. material, see www.karger.com/ doi/10.1159/000448243).

\section{Neuropsychological Measures}

A core battery of neuropsychological measures was administered to all participants at each visit [29]. All four cognitive domains documented in the UDS were evaluated: attention, executive functioning, language, and memory. Attention was assessed using the Digit Span subtest (Digits Forward) from the Wechsler Adult Intelligence Scale [30] and the Trail-Making Test Part A [31]. Executive functioning was quantified using the WAIS Digit Span test (Digits Backwards) [32] and Trail-Making Test Part B [29, 30]. Language was assessed using the 30-item version of the Boston Naming Test [33]. Memory was evaluated using the Logical Memory subtest from the Wechsler Memory Scale [33]. Table 2 notes the detailed neuropsychological characteristics of the subjects at initial and final visits.

\section{Statistical Analysis}

Tukey Kramer adjusted pairwise comparisons were undertaken to evaluate the demographic differences, initial and final neuropsychological variables, and pathology measures between the groups. A difference of $\mathrm{p} \leq 0.05$ was considered statistically significant.

To evaluate the rate of cognitive decline across the groups, an initial analysis of the matrix of population and demographic variables of interest using the co-linearity diagnostics of variance inflation and condition indices was performed. Results indicated that patient age, gender, APOE $\varepsilon 4$ status, diffuse and neuritic plaque burden, and mean duration of symptoms were sufficiently independent of one another to permit their inclusion in a multivariable analysis. Independent sample $t$ test was used for testing differences in mean slopes.

The method of repeated measures mixed models was next used to assess correlations between neuropsychological measures and these variables across time. The rate of change on CDR-G, CDR-SB, MMSE, and Logical Memory Immediate and Delayed recall were evaluated for assessing cognitive and functional decline. Backward elimination regression methods were used to construct reduced models for each of the neuropsychological measures. The reduced models only contained terms with significance $p \leq 0.05$. Comparisons of rates of decline were made using methods outlined by Larson [34].

All analyses were done with SAS software version 9.3. 
Table 2. Neuropsychological measures at initial and final visit

\begin{tabular}{|c|c|c|c|}
\hline & ADLBD & ADV & $\mathrm{pAD}$ \\
\hline \multicolumn{4}{|l|}{ Initial visit } \\
\hline CDR-G & $0.5(0)^{b}$ & $0.4(0.2)^{\mathrm{b}}$ & $0.4(0.2)$ \\
\hline CDR-SB & $2.5(1.1)^{\mathrm{b}}$ & $1.8(1.3)^{\mathrm{b}}$ & $2.1(1.4)$ \\
\hline Functional Activities Questionnaire & $10.1(6.8)$ & $9.1(7.1)$ & $7.6(7.2)$ \\
\hline MMSE & $25.0(3.1)$ & $25.3(3.5)$ & $25.6(3.5)$ \\
\hline Logical Memory: Learning & $7(4.6)^{\mathrm{a}}$ & $8.5(5.1)$ & $6.7(4.5)$ \\
\hline Logical Memory: Delayed recall & $6(4.6)^{\mathrm{a}}$ & $6.6(5.4)$ & $4.6(4.6)$ \\
\hline Digit Span - Forward & $6(1)$ & $6.1(1.1)$ & $6.2(1.2)$ \\
\hline Digit Span - Backward & $4(1)$ & $4.2(1.2)$ & $4(1.2)$ \\
\hline Trail-Making Test - Part A, s & $62.4(28)$ & $57(30)$ & $62(32)$ \\
\hline Trail-Making Test - Part B, s & $217.2(81.2)$ & $189.7(85.4)$ & $179.1(87.4)$ \\
\hline Boston Naming Test & $23.8(4.4)$ & $22.7(6)$ & $23.8(5.6)$ \\
\hline \multicolumn{4}{|l|}{ Final visit } \\
\hline CDR-G & $2.1(0.8)^{\mathrm{b}}$ & $1.7(0.8)^{\mathrm{a}, \mathrm{b}}$ & $2.1(0.8)^{\mathrm{a}}$ \\
\hline CDR-SB & $12.6(4.1)^{\mathrm{b}}$ & $10.2(4.7)^{\mathrm{a}, \mathrm{b}}$ & $12.5(4.5)^{\mathrm{a}}$ \\
\hline Functional Activities Questionnaire & $27.6(3.7)$ & $27.1(4.3)$ & $27.6(3.9)$ \\
\hline MMSE & $15.3(8)$ & $16.9(7.1)$ & $14.2(6.1)$ \\
\hline Logical Memory: Learning & $3.5(3.9)$ & $5.1(5.8)$ & $2.3(2.9)$ \\
\hline Logical Memory: Delayed recall & $2.8(3.4)$ & $2.9(4.6)$ & $1.1(2)$ \\
\hline Digit Span - Forward & $5.3(1.1)$ & $5.7(1.1)$ & $4.9(1.7)$ \\
\hline Digit Span - Backward & $2.4(1.5)$ & $3.3(1.2)$ & $2.9(1.3)$ \\
\hline Trail-Making Test - Part A, s & $102.4(48)$ & $98.1(39.8)$ & $104.5(48.9)$ \\
\hline Trail-Making Test - Part B, s & $262.7(81.6)$ & $203.9(101.9)$ & $227.4(82.6)$ \\
\hline Boston Naming Test & $19.3(7.5)$ & $17.9(6.7)$ & $15(8.5)$ \\
\hline
\end{tabular}

Values are expressed as mean (SD). $\mathrm{p}<0.01 .{ }^{\mathrm{a}}$ Significant difference between $\mathrm{pAD}$ and ADV. ${ }^{\mathrm{b}}$ Significant difference between ADV and ADLBD.

\section{Results}

\section{Subject Sample}

A total of 692 NACC subjects had a neuropathologic diagnosis in the pre-specified time frame. Of the 692 subjects, 169 subjects met all inclusion/exclusion clinical and pathological criteria. The flow chart for subject selection is included in the online supplementary figure 1. There were 84 pAD subjects, 54 ADV, and 31 ADLBD identified in this sample.

\section{Impact of Age on Dementia Types}

The percentage of individuals with $C D R-G \geq 1$ (stage of dementia) increased with age for all three pathology groups, but the mean age of transition to CDR-G $\geq 1$ was significantly younger in the ADLBD and pAD groups than in the ADV group (77.6, 77.9, and 85.8 years, respectively; $\mathrm{p}<0.0001$, Tukey-Kramer adjusted pairwise comparison).

The mean age at death was similar between ADLBD and pAD (79.3 vs. 80 years) but was significantly higher in ADV (87.5 years; $\mathrm{p}<0.0001$, Tukey-Kramer adjusted pairwise comparison) (table 1, fig. 1).

\section{Duration of Symptoms}

The duration of symptoms was calculated from the age estimated by the clinician as when the cognitive decline began to the age at death. The mean duration of symptoms was not 


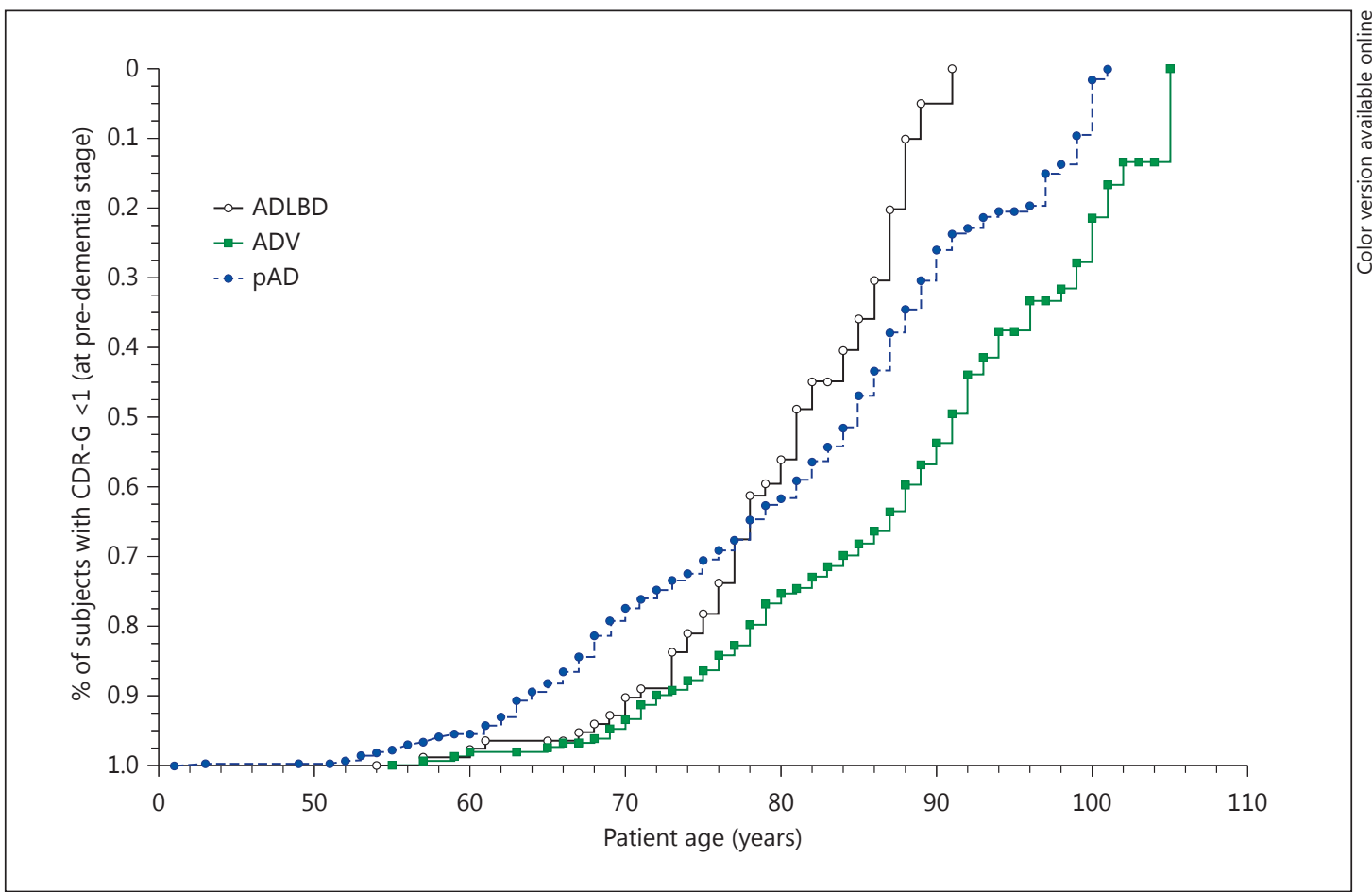

Fig. 1. Cumulative distribution of $C D R-G \geq 1$ versus patient age.

significantly different between the three groups ( $\mathrm{p}>0.05$, Tukey-Kramer adjusted pairwise comparison) (table 1).

The Fraction of Subjects Developing Dementia at Each Year of Longitudinal Follow-Up and the Odds of Dementia before Death

Even as the mean age of transition to CDR-G $\geq 1$ was different across the groups, the fraction of subjects attaining CDR-G $\geq 1$ at each year before death was similar irrespective of the pathology group. An analysis of the Kaplan-Meier curves indicated no significant differences between the groups. The log-rank test for differences between the curves was not significant ( $p=0.87$, fig. 2 ). As the mean age at death was significantly higher in ADV, after controlling for age at the last visit, the odds of an ADV subject with CDR $\geq 1$ at the last visit before death were $70 \%$ of those of a pAD subject (OR: $0.7,95 \% \mathrm{CI}: 0.50-0.96, \mathrm{p}<0.030$ ). The odds of an ADLBD subject with CDR $\geq 1$ at the last visit were not statistically greater than those of a pAD subject after controlling for age at the last visit (OR: 1.06, 95\% CI: 0.74-1.53, $\mathrm{p}=0.74)$.

The Severity of Cognitive and Functional Deficits at the Initial Visit and before Death among Dementia Types

The mean final CDR-G and CDR-SB scores were significantly lower in ADV versus pAD ( $p<0.01$, Tukey-Kramer adjusted pairwise comparisons). The initial and final CDR scores for ADLBD were similar to the pAD group but significantly higher than those of the ADV group ( $p<0.01$, corrected for multiple comparisons). Among other neuropsychology measures analyzed, no overall significant group differences were seen on any initial or final neuropsychology scores (table 2). When pairwise comparisons were examined, the Logical Memory 
Pillai et al.: Impact of Alzheimer's Disease, Lewy Body and Vascular Co-Pathologies on

Clinical Transition to Dementia in a National Autopsy Cohort

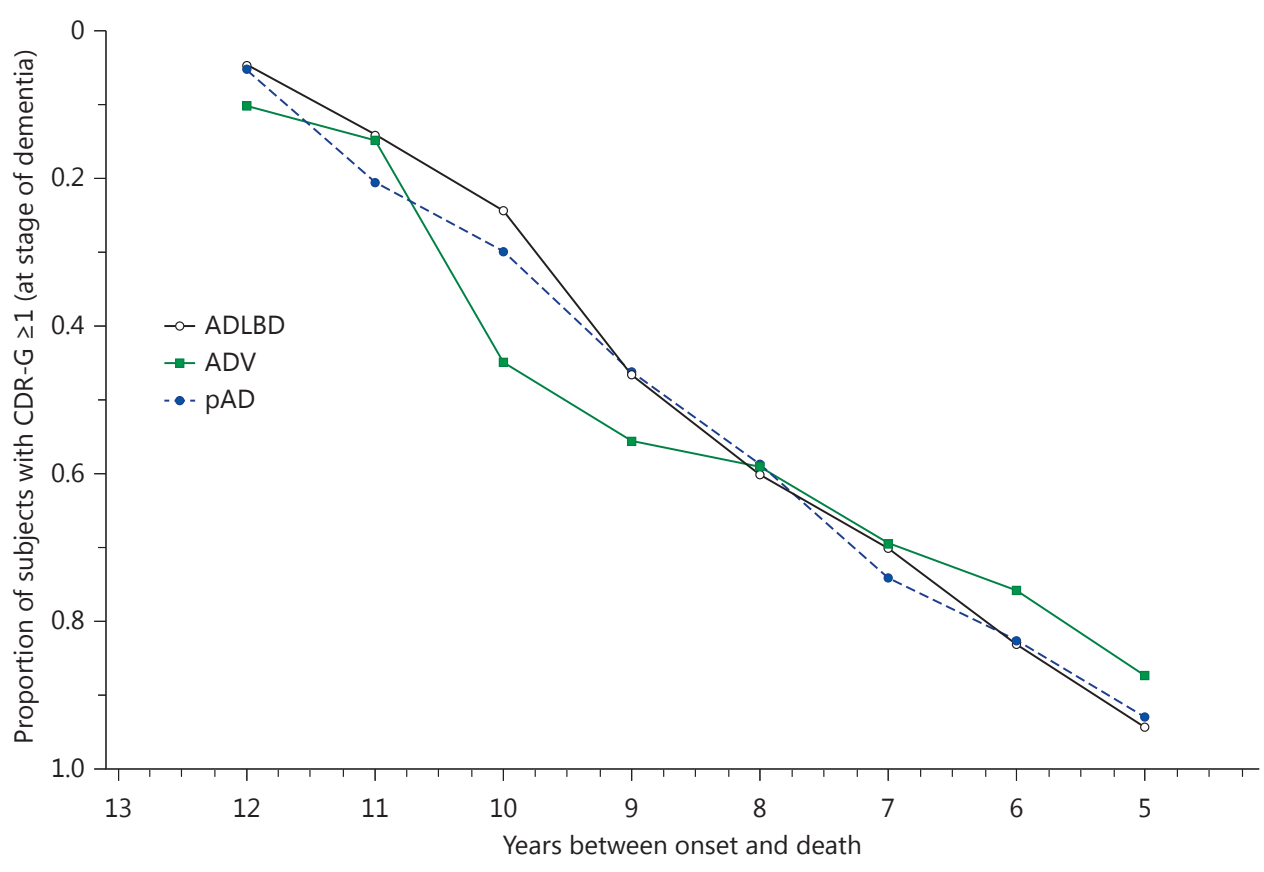

Fig. 2. Probability of dementia development ( $C D R-G \geq 1)$ versus time to death.

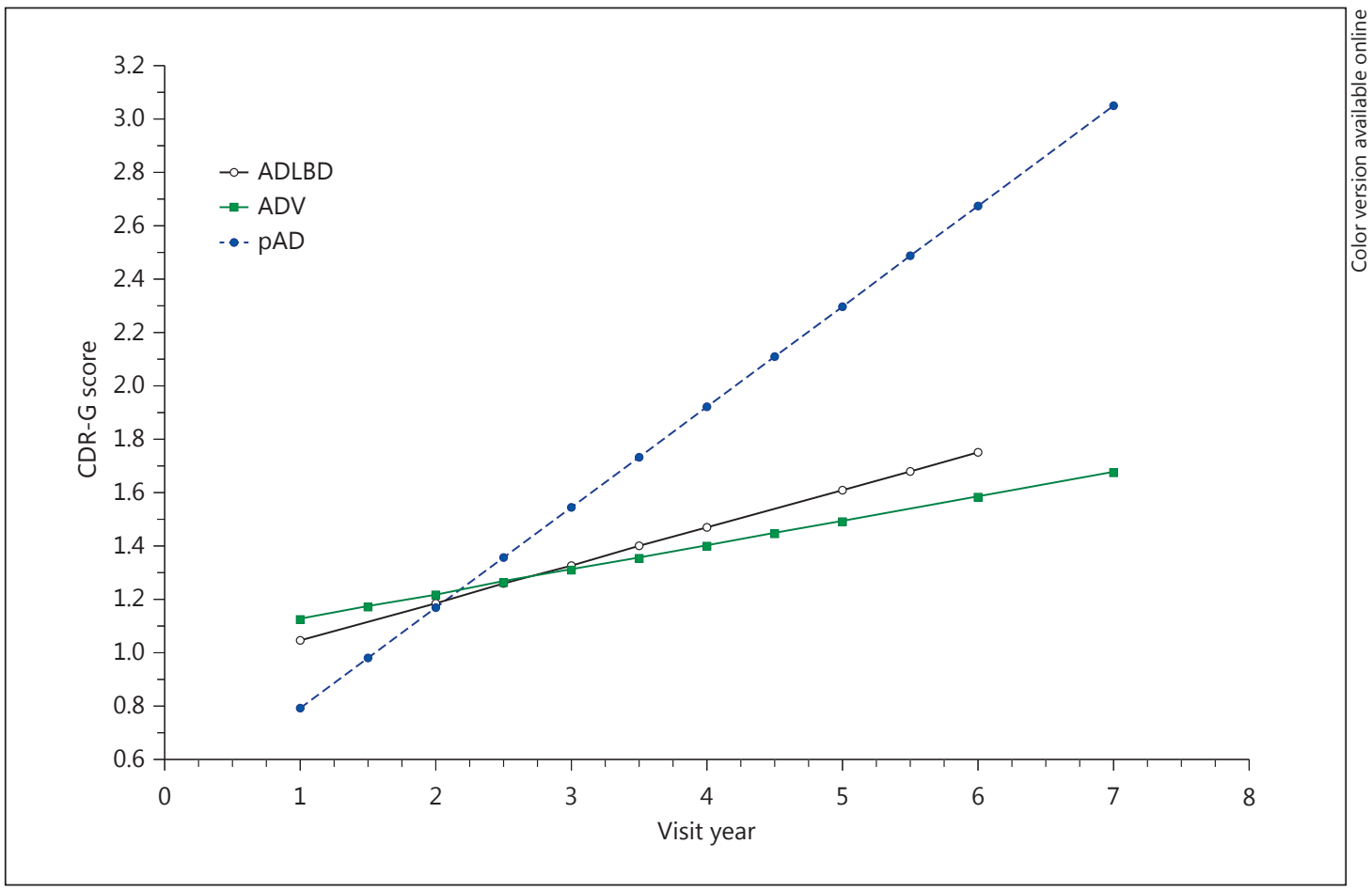

Fig. 3. Slope of CDR-G across patient ages by visit time. 
Table 3. Slope coefficients from repeated measures mixed models after controlling for age, sex, APOE $\varepsilon 4$ status, diffuse and neuritic plaque burden, and mean duration of symptoms

\begin{tabular}{llllll}
\hline & CDR-G & CDR-SB & MMSE & $\begin{array}{l}\text { Logical Memory: } \\
\text { Immediate recall }\end{array}$ & $\begin{array}{l}\text { Logical Memory: } \\
\text { Delayed recall }\end{array}$ \\
\hline pAD & $0.34^{\mathrm{a}}$ & $2.1^{\mathrm{a}}$ & $-2.43^{\mathrm{a}}$ & -0.99 & -0.81 \\
ADV & $0.22^{\mathrm{a}, \mathrm{b}}$ & $1.5^{\mathrm{a}, \mathrm{b}}$ & $-1.17^{\mathrm{a}, \mathrm{b}}$ & -0.41 & -0.36 \\
ADLBD & $0.378^{\mathrm{b}}$ & $2.3^{\mathrm{b}}$ & $-3.08^{\mathrm{b}}$ & -0.88 & -0.76 \\
\hline
\end{tabular}

$\mathrm{p}<0.01$ a $^{\mathrm{a}}$ Significant difference between $\mathrm{pAD}$ and ADV. ${ }^{\mathrm{b}}$ Significant difference between ADV and ADLBD.

Table 4. Neuropathology variables and duration of symptoms

\begin{tabular}{lllll}
\hline & $\begin{array}{l}\text { Duration of } \\
\text { symptoms, years }\end{array}$ & Braak stage & Diffuse plaques & $\begin{array}{l}\text { Neuritic } \\
\text { plaques }\end{array}$ \\
\hline pAD $(\mathrm{n}=82)$ & $8.46(3.4)$ & $5.4(0.81)^{\mathrm{a}, \mathrm{b}}$ & $1.2(0.39)^{\mathrm{a}}$ & $1.3(0.50)^{\mathrm{a}}$ \\
ADV $(\mathrm{n}=48)$ & $7.7(3.5)$ & $4.7(0.95)^{\mathrm{a}}$ & $1.5(0.87)^{\mathrm{a}}$ & $1.7(0.99)^{\mathrm{a}}$ \\
ADLBD $(\mathrm{n}=29)$ & $8.1(2.8)$ & $4.6(1.02)^{\mathrm{b}}$ & $1.3(0.65)$ & $1.5(0.72)$ \\
\hline
\end{tabular}

Values are expressed as mean (SD). $\mathrm{n}=$ Number of unique patients in duration of symptoms analysis as

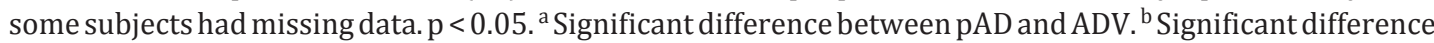
between ADV and ADLBD.

immediate recall score was different between the groups, with the pAD subjects having more deficits in Logical Memory at the final visit $(\mathrm{p}<0.05)$.

The Rate of Cognitive and Functional Decline among Dementia Types

In a repeated measures mixed model, the rate of decline (by visit number and also by subject age) on the CDR-SB, CDR-G, and MMSE scores in the ADV group was slower than in the ADLBD and pAD groups (CDR-SB, CDR-G, and MMSE: $p<0.0001$, independent samples $t$ test). This result was noted even after controlling for age, sex, APOE $\varepsilon 4$ status, years of education, duration of symptoms, and amyloid plaque and neurofibrillary tangle staging. No significant differences were noted in the rate of decline of Logical Memory Immediate and Delayed recall scores for the three groups (table 3, fig. 3).

\section{Severity of AD Neuropathology across Groups}

The pAD group had a mean Braak stage of 5.4 compared to the ADV (4.7) and ADLBD (4.6) groups ( $\mathrm{p}<0.001$, Tukey-Kramer adjusted pairwise comparisons). This was noted even after adjusting for the final MMSE scores and education. The pAD group also had concomitantly higher mean neuritic plaque and diffuse plaque burden than the ADV group (table 4).

\section{Discussion}

This study of a large autopsy sample of prospectively characterized subjects examined the conversion of subjects from a pre-dementia state to dementia. In this sample, ADV subjects were significantly older than both pAD and ADLBV subjects. However, even when controlling for age, we found that the $\mathrm{PAD}$ group had a more rapid rate of cognitive and functional decline 
Pillai et al.: Impact of Alzheimer's Disease, Lewy Body and Vascular Co-Pathologies on Clinical Transition to Dementia in a National Autopsy Cohort

and, not surprisingly, more severe functional and cognitive deficits before death than the ADV group. There were no significant differences found between pAD and ADLBD. Contrary to our initial hypotheses, MD was not associated with higher odds of dementia before death or with a faster rate of cognitive or functional decline.

At autopsy, the pAD subjects had a higher mean Braak stage and plaque count than the ADV subjects after controlling for age, sex, education, and APOE $\varepsilon 4$ status and despite similar dementia duration. It is notable that this result was found even after controlling for APOE $\varepsilon 4$ status, as APOE $\varepsilon 4$ carriers have been reported to accumulate amyloid at an earlier age and a faster rate than APOE \&4 noncarriers [35]. These results could be accounted for by the AD neuropathology accruing more rapidly in the $\mathrm{pAD}$ group, accounting for the more rapid rate of decline and greater severity of cognitive and functional deficits at the final visit before death. This might also indicate that AD pathology among the older ADV group is less aggressive. Alternatively, ADV subjects could have a lower mean Braak stage and plaque counts at initial cognitive symptoms due to coexistent vascular pathology contributing to their cognitive impairment $[11,12]$. As a previous report among subjects who exhibited silent infarcts on brain MRI reported a greater risk of developing dementia than those without these lesions [36], our results could also reflect a silent preclinical AD stage in the younger pAD subjects and a silent preclinical stage from vascular pathology among the older ADV subjects.

In our analysis cohort, $94 \%$ of the ADLBD subjects had either diffuse (neocortical) or intermediate (limbic) distribution of LB pathology. Our results, comparing pAD and ADLBD, showed no significant difference in the functional rate of decline or the probability of developing dementia prior to death. The groups also had a similar age at symptom onset and death and similar mean disease durations. The ADLBD group had a faster rate of decline on the CDR-G, CDR-SB, and MMSE compared to the ADV group despite similar Braak stage AD pathology. This difference between the ADV and mixed ADLBD groups suggests that LB pathology, in the context of $\mathrm{AD}$, may be a marker for a more aggressive form of MD. These results are similar to the reports from nondemented elders with $\mathrm{AD}$ and LB co-pathology in the Rush Memory and Aging project and Religious Orders Study, which noted that neocortical LBs were associated with a faster rate of decline (unlike the case for co-occurring vascular pathology) [19].

There are several weaknesses to this analysis. Any multisite study will have variability in assessments between sites. Seventy-five percent of the ADV subjects in our cohort had one or more large infarcts, microinfarcts, hemorrhages, and lacunes (online suppl. table 1 and 2), but systematic assessment of a known dementia-associated vascular pathology, microinfarcts, was not performed consistently across sites. In many longitudinal neurodegenerative cohorts, including the NACC, there is a selection bias as subjects with large hemispheric infarcts or a high burden of early-onset vascular cognitive deficits would not have been enrolled. We should therefore consider the possibility that the rate of functional decline might have been higher among younger-onset ADV subjects with more severe vascular co-pathology than that reported in the NACC data. The differences in the results noted between early $[1,10-14]$ and later MD reports [15-17] could also be due to similar differences in the cohorts and inclusion/ exclusion and diagnostic criteria. Additional biases can enter in a multicenter autopsy study: (1) differences among neuropathology analysis across centers; (2) evolution in diagnostic criteria and lack of uniform assessment of the vascular burden and LBD; (3) the likelihood of bias against subjects with rapid decline from AD, LBD or vascular pathology, and/or (4) limited neuropathology characterization of the severity of vascular and LB pathology.

Despite the limitations noted above, these results are consistent with the findings from the Religious Orders Study where vascular co-pathology did not contribute to a worse cognitive and functional outcome than when $\mathrm{AD}$ pathology was present alone, among nondemented adults, and did not increase the likelihood of dementia beyond their additive effect $[14,19]$. 


\section{Summary}

In the NACC longitudinal autopsy cohort, vascular co-pathology did not increase the odds of dementia onset, and ADV subjects had a slower rate of cognitive and functional decline and less severe deficits than $\mathrm{pAD}$ subjects. ADLBD subjects had a faster rate of functional decline and more severe deficits than ADV subjects but not compared to those with $\mathrm{pAD}$. These results suggest that the clinical course of MD is heterogeneous, and factors including the nature of co-pathology (vascular vs. LB), the type of population cohort (with varying severity of vascular and medical co-morbidities), neuropsychology profile [37], and the age of subjects need to be considered in the clinical prognosis of $\mathrm{AD}$ and $\mathrm{MD}$ subjects and in designing interventions. This study also provides an impetus to better understand the biological and environmental factors mediating the interaction between $\mathrm{AD}$, vascular, and LBD pathologies influencing functional decline.

\section{Acknowledgements}

The NACC database is funded by NIA/NIH Grant U01 AG016976. NACC data are contributed by the NIAfunded ADCs: P30 AG019610 (PI Eric Reiman, MD), P30 AG013846 (PI Neil Kowall, MD), P50 AG008702 (PI Scott Small, MD), P50 AG025688 (PI Allan Levey, MD, PhD), P30 AG010133 (PI Andrew Saykin, PsyD), P50 AG005146 (PI Marilyn Albert, PhD), P50 AG005134 (PI Bradley Hyman, MD, PhD), P50 AG016574 (PI Ronald Petersen, MD, PhD), P50 AG005138 (PI Mary Sano, PhD), P30 AG008051 (PI Steven Ferris, PhD), P30 AG013854 (PI M. Marsel Mesulam, MD), P30 AG008017 (PI Jeffrey Kaye, MD), P30 AG010161 (PI David Bennett, MD), P30 AG010129 (PICharles DeCarli, MD), P50 AG016573 (PI Frank LaFerla, PhD), P50 AG016570 (PI David Teplow, PhD), P50 AG005131 (PI Douglas Galasko, MD), P50 AG023501 (PI Bruce Miller, MD), P30 AG035982 (PI Russell Swerdlow, MD), P30 AG028383 (PI Linda Van Eldik, PhD), P30 AG010124 (PI John Trojanowski, MD, PhD), P50 AG005133 (PI Oscar Lopez, MD), P50 AG005142 (PI Helena Chui, MD), P30 AG012300 (PI Roger Rosenberg, MD), P50 AG005136 (PI Thomas Montine, MD, PhD), P50 AG033514 (PI Sanjay Asthana, MD, FRCP), and P50 AG005681 (PI John Morris, MD).

\section{Disclosure Statement}

A.B.-J. and R.S.B. have no disclosures.

J.A.P. has the following disclosures: grant support from Alzheimer's Association.

J.B.L. has the following disclosures: consulting fees from Axovant, GE Healthcare, Navidea Biopharmaceuticals, Piramal Healthcare, and Teva. Grant support from Alzheimer's Association, Alzheimer's Drug Discovery Foundataion, Axovant, Genzyme/Sanofi, Lundbeck, Michael J. Fox Foundation, and National Institute of Health.

\section{References}

1 Snowdon DA, Greiner LH, Mortimer JA, et al: Brain infarction and the clinical expression of Alzheimer disease. The Nun Study. JAMA 1997;277:813-817.

2 White L, Petrovitch H, Hardman J, et al: Cerebrovascular pathology and dementia in autopsied Honolulu-Asia Aging Study participants. Ann NY Acad Sci 2002;977:9-23.

3 Neuropathology Group of the Medical Research Council Cognitive Function and Aging Study (MRC CFAS): Pathologic correlates of late onset dementia in a multicentre, community-based population in England and Wales. Lancet 2001;357:169-175.

4 Schneider JA, Arvanitakis Z, Bang W, Bennett DA: Mixed brain pathologies account for most dementia cases in community-dwelling older persons. Neurology 2007;69:2197-2204.

5 Barker WW, Luis CA, Kashuba A, Luis M, Harwood DG, Loewenstein D, Waters C, Jimison P, Shepherd E, Sevush S, Graff-Radford N, Newland D, Todd M, Miller B, Gold M, Heilman K, Doty L, Goodman I, Robinson B, Pearl G, Dickson D, Duara R: Relative frequencies of Alzheimer disease, Lewy body, vascular and frontotemporal dementia, and hippocampal sclerosis in the State of Florida Brain Bank. Alzheimer Dis Assoc Disord 2002;16:203-212.

6 Jellinger KA, Attems J: Neuropathological evaluation of mixed dementia. J Neurol Sci 2007;257:80-87. 
7 Kovacs GG, Milenkovic I, Wohrer A, Hoftberger R, Gelpi E, Haberler C, Hönigschnabl S, Reiner-Concin A, Heinzl H, Jungwirth S, Krampla W, Fischer P, Budka H: Non-Alzheimer neurodegenerative pathologies and their combinations are more frequent than commonly believed in the elderly brain: a community-based autopsy series. Acta Neuropathol 2013;126:365-384.

8 Rahimi J, Kovacs GG: Prevalence of mixed pathologies in the aging brain. Alzheimers Res Ther 2014;6:82.

9 Schneider JA, Arvanitakis Z, Leurgans SE, Bennett DA: The neuropathology of probable Alzheimer disease and mild cognitive impairment. Ann Neurol 2009;66:200-208.

10 Markesbery WR: Comments on vascular dementia. Alzheimer Dis Assoc Disord 1991;5:149-153.

11 Riekse RG, Leverenz JB, McCormick W, Bowen JD, Teri L, Nochlin D, Simpson K, Eugenio C, Larson EB, Tsuang D: Effect of vascular lesions on cognition in Alzheimer's disease: a community-based study. J Am Geriatr Soc 2004;52:1442-1448.

12 Esiri MM, Nagy Z, Smith MZ, Barnetson L, Smith AD: Cerebrovascular disease and threshold for dementia in the early stages of AD. Lancet 1999;354:919-920.

13 Mungas D, Reed BR, Ellis WG, Jagust WJ: The effects of age on rate of progression of Alzheimer disease and dementia with associated cerebrovascular disease. Arch Neurol 2001;58:1243-1247.

14 Schneider JA, Wilson RS, Bienias JL, Evans DA, Bennett DA: Cerebral infarctions and the likelihood of dementia from Alzheimer disease pathology. Neurology 2004;62:1148-1155.

15 Lo RY, Jagust WJ; Alzheimer's Disease Neuroimaging Initiative: Vascular burden and Alzheimer disease pathologic progression. Neurology 2012;79:1349-1355.

16 Villeneuve S, Reed BR, Madison CM, Wirth M, Marchant NL, Kriger S, Mack WJ, Sanossian N, DeCarli C, Chui HC, Weiner MW, Jagust WJ: Vascular risk and A $\beta$ interact to reduce cortical thickness in AD vulnerable brain regions. Neurology 2014;83:40-47.

17 Vemuri P, Lesnick TG, Przybelski SA, Knopman DS, Preboske GM, Kantarci K, Raman MR, Machulda MM, Mielke MM, Lowe VJ, Senjem ML, Gunter JL, Rocca WA, Roberts RO, Petersen RC, Jack CR Jr: Vascular and amyloid pathologies are independent predictors of cognitive decline in normal elderly. Brain 2015;138:761-771.

18 Chui HC, Zheng L, Reed BR, Vinters HV, Mack WJ: Vascular risk factors and Alzheimer's disease: are these risk factors for plaques and tangles or for concomitant vascular pathology that increases the likelihood of dementia? An evidence-based review. Alzheimers Res Ther 2012;4:1.

19 Boyle PA, Yu L, Wilson RS, Schneider JA, Bennett DA: Relation of neuropathology with cognitive decline among older persons without dementia. Front Aging Neurosci 2013;5:50.

20 Walker L, McAleese KE, Thomas AJ, Johnson M, Martin-Ruiz C, Parker C, Colloby SJ, Jellinger K, Attems J: Neuropathologically mixed Alzheimer's and Lewy body disease: burden of pathological protein aggregates differs between clinical phenotypes. Acta Neuropathol 2015;129:729-748.

21 Breitve MH, Chwiszczuk LJ, Hynninen MJ, Rongve A, Brønnick K, Janvin C, Aarsland D: A systematic review of cognitive decline in dementia with Lewy bodies versus Alzheimer's disease. Alzheimers Res Ther 2014;6:5.

22 Olichney JM, Galasko D, Salmon DP, Hofstetter CR, Hansen LA, Katzman R, Thal LJ: Cognitive decline is faster in Lewy body variant than in Alzheimer's disease. Neurology 1998;51:351-357.

23 Kraybill JL, Larson EB, Tsuang DW, Teri L, McCormick WC, Bown JD, et al: Cognitive differences in dementia patients with autopsy-verified AD, Lewy body pathology, or both. Neurology 2005;64:2069-2073.

24 Beekly DL, Ramos EM, Lee WW, Deitrich WD, Jacka ME, Wu J, Hubbard JL, Koepsell TD, Morris JC, Kukull WA; NIA Alzheimer's Disease Centers: The National Alzheimer's Coordinating Center (NACC) database: the Uniform Data Set. Alzheimer Dis Assoc Disord 2007;21:249-258.

25 Morris JC: The Clinical Dementia Rating (CDR): current version and scoring rules. Neurology 1993;43:2412-2414.

26 Folstein MF, Folstein SE, McHugh PR: 'Mini-mental state': a practical method for grading the cognitive state of patients for the clinician. J Psychiatr Res 1975;12:189-198.

27 Hyman, BT, Phelps CH, Beach TG, et al: National Institute on Aging - Alzheimer's Association guidelines for the neuropathologic assessment of Alzheimer's disease. Alzheimers Dement 2012;8:1-13.

28 Brenowitz WD, Nelson PT, Besser LM, Heller KB, Kukull WA: Cerebral amyloid angiopathy and its co-occurrence with Alzheimer's disease and other cerebrovascular neuropathologic changes. Neurobiol Aging 2015; 36:2702-2708.

29 Weintraub S, Salmon D, Mercaldo, Ferris S, Graff-Radford NR, Chui H, Cummings J, DeCarli C, Foster NL, Galasko D, Peskind E, Dietrich W, Beekly DL, Kukull WA, Morris JC, et al: The Alzheimer's Disease Centers' Uniform Data Set (UDS): the neuropsychologic test battery. Alz Dis Assoc Disord 2009;23:91-101.

30 Wechsler D: The Wechsler Adult Intelligence Scale - Revised. San Antonio, Psychological Corporation, 1981.

31 Army Individual Test Battery: Manual of Directions and Scoring. Department of Health and Human Services, Washington, DC: War Department, Adjutant General's Office, 1944.

32 Kaplan E, Goodglass H, Weintraub S: Boston Naming Test. Philadelphia. Lea \& Febiger, 1983.

33 Wechsler D: Wechsler Memory Scale - Revised. San Antonio, Psychological Corporation, 1987.

34 Larson D: Analysis of variance with just summary statistics as input. Am Stat 1992;46:151-152.

35 Jack CR Jr, Wiste HJ, Weigand SD, Knopman DS, Vemuri P, Mielke MM, Lowe V, Senjem ML, Gunter JL, Machulda MM, Gregg BE, Pankratz VS, Rocca WA, Petersen RC: Age, sex, and APOE $\varepsilon 4$ effects on memory, brain structure, and $\beta$-amyloid across the adult life span. JAMA Neurol 2015;72:511-519.

36 Vermeer SE, Prins ND, den Heijer T, Hofman A, Koudstaal PJ, Breteler MM: Silent brain infarcts and the risk of dementia and cognitive decline. N Engl J Med 2003;348:1215-1222.

37 Pillai JA, Bonner-Jackson A, Walker E, Mourany L, Cummings JL: Higher working memory predicts slower functional decline in autopsy-confirmed Alzheimer's disease. Dement Geriatr Cogn Disord 2014;38:224-233. 